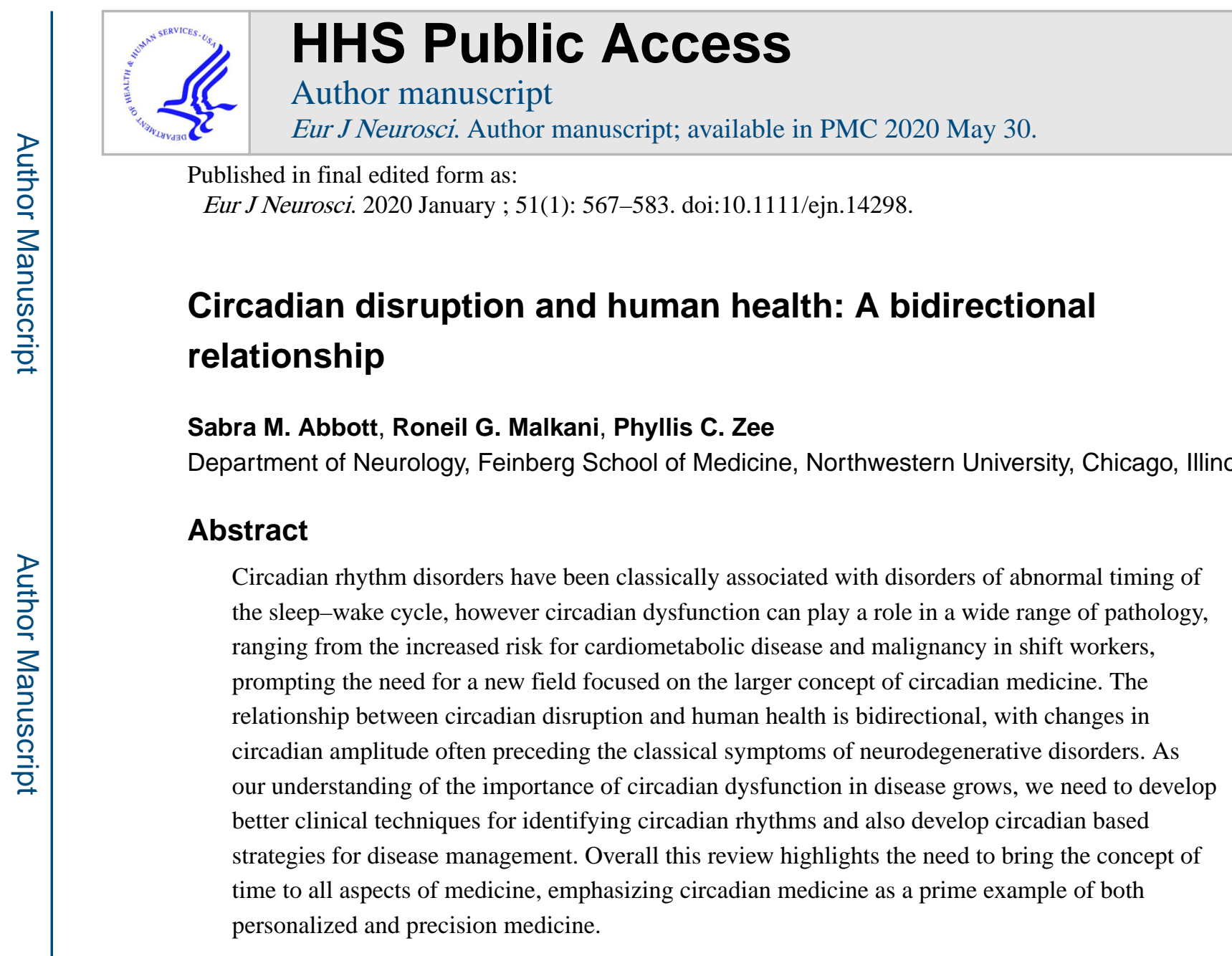

\title{
Keywords
}

chronotherapy; melatonin; neurodegenerative disease; shift work

\section{1| INTRODUCTION}

Circadian rhythms and sleep are fundamental biological imperatives, and are often challenged by changes in the environment, unhealthy behaviors, and disease, leading to misalignment among internal biological clocks and/or with the external physical environment or social behaviors. In the past decade, fundamental basic science discoveries have demonstrated that circadian clocks are integrated into the regulation of biological processes in all tissues. Advances in the scientific knowledge of the molecular and cellular underpinnings of circadian biology, indicate that circadian disruption plays a central role in the expression and development of cardiometabolic, cognitive and mood disorders. As an example, the core clock genes involved in regulating circadian rhythms are present not only

Correspondence: Sabra M. Abbott, Department of Neurology, Feinberg School of Medicine, Northwestern University, Chicago, IL. sabra.abbott@ northwestern.edu. AUTHOR CONTRIBUTIONS

SMA, RM, and PCZ drafted the manuscript. SMA and PCZ revised the original draft and provided additional input. All authors critically revised the manuscript and approved its final version.

CONFLICT OF INTEREST

Authors declare no conflict of interest. 
in the suprachiasmatic nucleus, but also in the liver and pancreas, resulting in the coordinated circadian regulation of metabolism and catabolism (Dibner \& Schibler, 2015).

However, the coordinated timing of these biological processes conflicts with our increasingly 24-7 society. Individuals are more frequently working and eating at odds with their biological clock, leading to a chronic misalignment between biological timing and behavior. This misalignment appears to increase the risk for chronic disease, with impact seen in many areas of human health, including hypertension, diabetes, and cancer risk (Forman, Curhan, \& Schernhammer, 2010; McMullan, Schernhammer, Rimm, Hu, \& Forman, 2013; Schernhammer et al., 2001). Interestingly, this relationship appears to be bidirectional, with some disease processes also associated with altered circadian function as an early symptom of the disorder. One example of this is the area of neurodegeneration, where circadian instability can be seen years before other clinical symptoms of cognitive impairment become apparent (Tranah et al., 2011). Thus, alterations in circadian timing have broad implications for overall health (Figure I).

Overall the time is ripe to translate these basic scientific findings into clinical interventions targeting the circadian system in order to improve overall health. This review will discuss what is currently understood about the role of circadian dysfunction in human disease and highlight our recent research in this area. We will also discuss new advances in diagnostic techniques to identify circadian health and dysfunction. Using this knowledge, we can begin to focus on the role of timing in medical treatment. Ultimately we will demonstrate that the future of circadian medicine is to become a hallmark of both personalized and precision medicine (Figure I).

\section{2 | CLASSICAL VIEW OF DISORDERS OF CIRCADIAN RHYTHMS}

Classically, disorders of circadian rhythms have been limited to their adverse effects on sleep, and thus the six primary circadian rhythm sleep wake disorders (CRSWDs) are considered within the domain of sleep medicine. Broadly speaking, CRSWDs result when there is misalignment between an individual's internal rhythm and the required timing of their daily activities. The six major recognized CRSWDs include: delayed sleep wake phase disorder (DSWPD), advanced sleep wake phase disorder (ASWPD), non-24 hr sleep wake disorder (N24SWD), irregular sleep wake rhythm disorder (ISWRD), shift-work disorder and jet lag disorder.

In DSWPD individuals have normal quality and duration of sleep, but their sleep window occurs several hours later than in the general population (Kripke et al., 2008). While the etiology remains unclear, there are reports of individuals with DSWPD having a longer intrinsic period than the general population (Campbell \& Murphy, 2007), and there are also theories that they may have increased sensitivity to the delaying effects of evening light (Aoki, Ozeki, \& Yamada, 2001), or decreased sensitivity to the advancing effects of morning light. More recently a familial form of DSWPD has been identified, associated with a mutation in the CRY1 gene (Patke et al., 2017). 
Individuals with ASWPD fall asleep several hours earlier than the general population, but again if allowed to sleep during their desired time window, sleep quality and duration are normal for age (American Academy of Sleep Medicine, 2014). There is a strong familial component to ASWPD, with mutations demonstrated in casein kinase I $\delta$ (Xu et al., 2005), and the casein kinase I $\varepsilon$ (CKI $\varepsilon$ ) binding region of hPER2 (Toh et al., 2001) and in CRY2 (Hirano et al., 2016). These mutations result in a more rapid progression through the transcription/translation feedback loop, leading to an overall shorter intrinsic circadian period (Shanware et al., 2011).

In N24SWD individuals again have normal duration and quality of sleep, but the sleep window occurs progressively later every day. This is most commonly seen in blind individuals, likely reflecting the underlying intrinsic circadian period, as they are no longer able to receive daily entraining signals from environmental light (American Academy of Sleep Medicine, 2005). Recent studies have demonstrated a lack of entrainment in $39 \%$ and abnormal entrainment in $24 \%$ of individuals with no light perception (Flynn-Evans, Tabandeh, Skene, \& Lockley, 2014). While more rare, this disorder can also occur in sighted individuals, and is thought to be due to multiple factors, including a prolonged intrinsic circadian period (Kitamura et al., 2012), decreased responsiveness to environmental entraining signals, and decreased social cues (Brown, Quan, \& Eichling, 2011; Kuzniar, Kovacevic-Ristanovic, Nierodzik, \& Smith, 2012).

Individuals with ISWRD have at least three separate sleep periods spread throughout the day, though if added up, the total duration of sleep in a $24 \mathrm{hr}$ period is normal for age (American Academy of Sleep Medicine, 2014). ISWRD is most often seen in children with neurodevelopmental disabilities (Okawa et al., 1991) and elderly institutionalized individuals (Zee \& Vitiello, 2009). The underlying etiology is thought to be due to a combination of degeneration of the suprachiasmatic nucleus (SCN) and either decreased sensitivity to or decreased exposure to environmental time cues (Abbott \& Zee, 2015).

Shift work disorder is characterized by sleep-wake disturbances lasting at least 3 months, resulting from being required to work during the desired sleep period (American Academy of Sleep Medicine, 2014). Individuals with morning-type tendencies, increased daytime social demands, and who require long-sleep times ( $>8 \mathrm{hr}$ ) are more likely to develop shift work disorder (Colligan \& Rosa, 1990). Symptoms generally resolve with resumption of a normal work schedule.

Jet lag disorder results when there is a mismatch between the endogenous sleep-wake cycle and the environmental sleep-wake cycle resulting from a change in time zones. Symptoms include insomnia and/or daytime sleepiness, impaired daytime function as well as occasional somatic symptoms such as gastrointestinal distress (American Academy of Sleep Medicine, 2014).

While the above represent the classical view of the primary clinical circadian disorders, circadian dysfunction is increasingly recognized as playing a role in nearly all aspects of human health and disease, as will be discussed in the next section. 


\section{3 | FUTURE OF CIRCADIAN RHYTHM DISORDERS}

There has been increasing recognition that circadian dysfunction plays an important role in a variety of disease models beyond the traditional sleep-wake disorders. We will highlight several examples of those here, starting with the health consequences of circadian disruption, most often seen in shift workers but also encountered in social jet lag. Social jet lag is a term used to define the difference between the sleep-wake schedule on work and non-work days. We will then discuss neurodegenerative disorders, where circadian dysfunction can often serve as an early marker of disease pathology. Specifically we highlight our work focused on the relationship between circadian dysfunction in cardiometabolic disease and neurodegeneration, and the potential for circadian based treatments to alter the development and expression of these conditions.

\subsection{Shift work and chronic disease}

Shift work is one of the most common causes of circadian disruption in our society, increasing the risk for cardiometabolic disease and cancer. Several case-control studies in Norway (Tynes, Hannevik, Andersen, Vistnes, \& Haldorsen, 1996) and the US (Davis, Mirick, \& Stevens, 2001) demonstrated an increased risk for breast cancer in women who worked overnight shifts. A retrospective analysis of data from one of the largest population based studies of the health effects of shift work, the Nurses' Health Study (NHS), found that women who worked the night shift for 30 or more years had an increased risk of developing breast cancer (Schernhammer et al., 2001). These results prompted the International Agency for the Research on Cancer in 2007 to conclude that shift work that involves circadian disruption is probably carcinogenic (Group 2A; Straif et al., 2007). Several recent studies have replicated these findings. In a case-control study in France, women with newly diagnosed breast cancer were more likely to have worked overnight shifts, with the risk being highest among women who had worked night shifts for $>4$ years before their first fullterm pregnancy (Menegaux et al., 2012). A Danish study looking at female military employees also showed an increased risk of breast cancer among those women who worked night shifts, with the effect being most pronounced among woman with a strong morning chronotype preference and high level of exposure to night shift work (Hansen \& Lassen, 2012). Similar results have also been shown in a cohort of Norwegian nurses (Lie, Roessink, $\&$ Kjaerheim, 2006) and Chinese women (Pronk et al., 2010). Multiple factors likely contribute to this increased risk including increased light exposure at night (O'Leary et al., 2006) and the circadian disruption associated with shift work. Both of these are likely mediated by decreased melatonin levels, as melatonin levels are suppressed by light, and melatonin is thought to have tumor suppressant properties.

Shift work also appears to play an important role in the development of cardiometabolic disease. Circadian disruption through shift work models in rodents have demonstrated an increase in insulin resistance and obesity (Shi, Ansari, McGuinness, Wasserman, \& Johnson, 2013) as well as metabolic dysfunction (Barclay et al., 2012) while subjecting humans to experimental models of shift work results in increased leptin levels (Nguyen \& Wright, 2010). The NHS demonstrated that increased cumulative exposure to shift work results in increased risk for ischemic stroke (Brown et al., 2009) and diabetes (Pan, Schernhammer, 
Sun, \& Hu, 2011). In addition, in this population, low urinary melatonin levels, presumably serving as a marker of underlying circadian disruption, have been associated with an increased risk of hypertension (Forman et al., 2010) and diabetes (McMullan et al., 2013). Similar data was found in a large Swedish cohort, noting an increased risk for obesity, lipid abnormalities and impaired glucose tolerance among shift workers (Karlsson, Knutsson, \& Lindahl, 2001) and a Danish cohort demonstrating an increased incidence of diabetes among night shift workers (Hansen, Stayner, Hansen, \& Andersen, 2016). In the UK biobank study of 277,168 workers, shift work was associated with an increased risk for obesity and disturbed sleep (Wyse et al., 2017). The underlying cause of the correlation between shift work and cardiometabolic disease is still unclear, though a Finnish study demonstrated these effects persisted, despite controlling for education, smoking, physical activity, alcohol use and insomnia (Puttonen, Viitasalo, \& Harma, 2012). Recent data obtained during simulated shiftwork conditions demonstrated a decrease in total energy expenditure, despite similar total activity and food intake when following a simulated night shift schedule compared to a daytime schedule (McHill et al., 2014).

\subsection{Circadian misalignment and cardiometabolic disorders}

There is growing evidence that circadian disruption through non-shift workers experiencing social jet lag can also increase the risk for a variety of medical illnesses. This difference is generally greatest in individuals who identify themselves as late chronotypes (preferring to go to bed and wake up later) but are required to work a traditional schedule (Wittmann, Dinich, Merrow, \& Roenneberg, 2006). Recent studies have demonstrated a correlation between social jetlag, and increased BMI (Roenneberg, Allebrandt, Merrow, \& Vetter, 2012), suggesting that even in non-shift workers misalignment between desired and actual sleep times can have potential negative health impacts. Along those lines, diabetic individuals with later sleep-wake timing, as determine based on the midpoint of habitual sleep timing have been noted to have poorer glucose control (Reutrakul et al., 2013). Our group has demonstrated in the Hispanic Community Health Study/Study of Latinos (HCHS/ SOL) Cohort Study that individuals both with and without diabetes had an association between later sleep-wake timing, and greater insulin resistance (Knutson et al., 2017). We demonstrated similar results in a large cohort of pregnant women who completed actigraphy measures. Actigraphy consists of an accelerometer that is usually worn on the non-dominant wrist, and can provide an objective measurement of activity and rest periods. Based on these measures, individuals with a later midpoint of sleep had an increased risk for developing gestational diabetes (Facco et al., 2017). In addition we found a small population of overweight/obese individuals, sleeping closer to the time of dim light melatonin onset, suggesting misalignment of sleep-wake and biological timing, was associated with decreased insulin sensitivity (Baron, Reid, Wolfe, Attarian, \& Zee, 2018). Along with later timing, decreased interdaily stability, a measure of the regularity of daily rhythms, has been demonstrated to be associated with increased risk for obesity, diabetes, hypertension and dyslipidemia (Sohail, Yu, Bennett, Buchman, \& Lim, 2015).

One factor that may be contributing to these findings is light exposure. Light is one of the primary entraining signals of the human circadian clock, and there is growing evidence that both timing and amplitude of light exposure are important. A recent study from our group 
found that being exposed to the majority of the total daily bright light later in the day is associated with having a higher body mass index (Reid et al., 2014). In addition, we recently demonstrated in a small study that exposure to blue-enriched light at the time of a meal was associated with increased insulin resistance (Cheung et al., 2016).

\subsection{Neurodegenerative disorders}

Circadian disruption also appears to play a key role in neurodegenerative disorders, and here the bidirectional relationship between circadian disruption and disease pathology becomes clearer.

3.3.1 Parkinson disease-Parkinson's disease (PD) is a neurodegenerative disorder characterized by bradykinesia, rigidity, and tremor. The pathological hallmark is the accumulation of Lewy bodies, comprised of intraneuronal a-synuclein inclusions, in the dopamine-containing nigrostriatal neurons. Sleep and wake disturbances, particularly sleep fragmentation and hypersomnia are common. It has been postulated that circadian rhythm disturbances underlie not only these sleep disturbances but also the pathophysiology of PD.

Data from clinical studies have shown alterations in various rhythms in PD, reflecting overall reduction in circadian amplitude. Studies using wrist actigraphy have shown that people with PD have decreased overall activity and increased nocturnal activity, leading to low amplitude of the rest/activity rhythm (van Hilten et al., 1994; Whitehead, Davies, Playfer, \& Turnbull, 2008). Those with more severe disease and hallucinations have even lower amplitudes and less interdaily stability of the rest/activity rhythms (Whitehead et al., 2008). Alterations in other rhythms such as blood pressure (Stuebner et al., 2013), core body temperature (Zhong, Bolitho, Grunstein, Naismith, \& Lewis, 2013) and cortisol rhythm (Hartmann, Veldhuis, Deuschle, Standhardt, \& Heuser, 1997) have also been observed. Cause and effect remain unclear as there is some evidence from animal models that circadian dysregulation may actually increase the risk for developing motor dysfunction, with a proposed mechanism of triggering a neuroinflammatory response, with increased neurodegeneration of the nigro-striatal pathway (Lauretti, Di Meco, Merali, \& Pratico, 2017).

Alternatively, circadian dysregulation may be a symptom of underlying neurodegeneration, however mechanisms underlying these circadian alterations remain unclear. The potential sites of disruption may include alteration of zeitgebers (time cues), afferents to the SCN (e.g., retina), the SCN itself, or downstream efferents. With aging, adults have decreased retinal illumination due to meiosis and decreased transmission of light through the lens (Turner \& Mainster, 2008). Additionally, people with PD may be more likely to stay indoors due to motor problems, leading to less light exposure during the day (Van Someren, 2000) but get an inappropriate increase in light exposure during the night due to sleep disruption (Rutten et al., 2012).

Dopamine, one of the major neurotransmitters affected in PD may influence the ability to respond to light. Dopamine enhances melanopsin expression in retinal ganglion cells that project to the SCN (Sakamoto et al., 2005) and may mediate the ability of light to reset retinal Per2 rhythms (Ruan, Allen, Yamazaki, \& McMahon, 2008). However, whether or not 
a change in dopamine metabolism or dopaminergic treatment in PD alters the circadian response to light has not been specifically examined. Dopamine metabolism in downstream brain areas involved in PD may also be disrupted. In striatal neurons, dopamine influences circadian gene expression, in particular Per1 and Per2. Per2, in turn, modulates dopamine levels through expression of the gene encoding monoamine oxidase-A (Hampp \& Albrecht, 2008). In addition, the absorption of levodopa, a dopamine agonist is slower at night, which also needs to be taken into account in the treatment of PD (Nyholm, Lennernas, Johansson, Estrada, \& Aquilonius, 2010). Therefore, changes in dopamine regulation in PD or treatment with dopaminergic medications could have effects on the circadian system at multiple levels.

The interaction between the circadian system and dopamine is particularly relevant because dopamine plays a role in regulating sleep/wake state. Dopamine in the ventral tegmental area and substantia nigra interact with the raphe nuclei, the locus coeruleus, the hypothalamus, the basal forebrain, and the thalamus, all of which are key nuclei in mediating sleep/wake states (Rye, 2004). The specific effect of dopamine on sleep/wake state depends on the type of dopamine receptor and the dose of agonist or antagonist. (Monti \& Jantos, 2008). Patients with PD treated with dopamine agonists-which target primarily D2 and D3 dopamine receptors-often report excessive sleepiness and may even have sleep attacks (Paus et al., 2003). Therefore, dysfunction in dopamine levels or alteration in dopamine receptor activity may lead to abnormal sleep/wake rhythms.

Dysfunction within the SCN itself could also contribute to circadian disruption. Decreased spontaneous firing of SCN neurons, sleep fragmentation, and increased variability in activity onset has been observed in a mouse model of PD (Kudo, Loh, Truong, Wu, \& Colwell, 2011). This decrease in synaptic transmission may lead to an impaired ability of the SCN to drive peripheral rhythms (Kudo et al., 2011). In addition, in humans, imaging studies have demonstrated significant volume loss in the hypothalamus compared to healthy controls (Breen et al., 2016).

Another potential link between PD and circadian rhythms may lie in the relationship between melatonin and the pathophysiology of PD. Reduced amplitude and a phase advance of melatonin rhythms has been observed in people with PD (Bordet et al., 2003; Fertl, Auff, Doppelbauer, \& Waldhauser, 1993) with the lowest amplitude found in those with the greatest degree of daytime sleepiness (Videnovic et al., 2014). In addition to chronobiotic effects, melatonin may protect mitochondria from damage through its action as a free radical scavenger and by upregulating other antioxidant enzymes (Cardinali, Pagano, Scacchi Bernasconi, Reynoso, \& Scacchi, 2013). Additionally, melatonin appears to inhibit asynuclein expression in dopaminergic neurons (Sae-Ung, Ueda, Govitrapong, \& PhansuwanPujito, 2012) and inhibits formation of toxic a-synuclein aggregates (Ono et al., 2012). Mitochondrial dysfunction may cause reduced SCN activity due to impaired ability to generate the energy required for peak daytime firing of the SCN neurons (Martin et al., 2006; Wang \& Huang, 2006).

Given these relationships between circadian dysfunction and PD, chronotherapeutics to improve circadian amplitude might be beneficial in the treatment of $\mathrm{PD}$, but data are sparse. Melatonin (3-5 mg) at bedtime has been shown to improve subjective sleep quality 
(Medeiros et al., 2007), subjective sleep quantity and daytime sleepiness (Dowling et al., 2005; Medeiros et al., 2007). With high doses of melatonin (50 mg) only a small objective improvement in sleep duration was seen (Dowling et al., 2005). Only a few studies have examined the effect of light therapy in PD. A large open-label retrospective study of bright light therapy $1 \mathrm{hr}$ before bedtime showed improvement in insomnia symptoms and motor symptoms in those adherent to treatment (Willis, Moore, \& Armstrong, 2012). One small prospective study of bright light therapy before bedtime for 2-5 weeks showed a decrease in sleep onset and an increase in sleep efficiency, as well as improvement in motor symptoms and mood. In a controlled prospective study of bright light therapy in PD, light therapy of 7,500 lux for $30 \mathrm{~min}$ in the morning resulted in improvement in subjective motor symptoms and mood but not objective motor symptoms (Paus et al., 2007). Finally, a randomized trial comparing twice daily bright light therapy to dim red light demonstrated a significant improvement in daytime sleepiness, self-reported sleep quality, and increased daily activity (Videnovic et al., 2017). The beneficial effect of light could be related to restoration of dopamine and melatonin balance (Willis et al., 2012). To date, studies of melatonin and bright light therapy have focused on their effects on sleep but not on disease progression or circadian markers.

Given the bidirectional relationship between dopamine metabolism and circadian function, we need a better understanding of how the timing and dose of dopaminergic therapy affects circadian rhythms, not just sleep (Wailke, Herzog, Witt, Deuschl, \& Volkmann, 2011). Further studies are needed to examine how circadian dysfunction relates to the pathophysiology of PD. Understanding whether circadian dysfunction promotes or perhaps even induces the pathological processes in PD or vice versa may open new avenues for the prevention and treatment of PD. Studies examining the effect of chronotherapeutics on PD should include not just sleep but also other circadian measures.

3.3.2 Alzheimer disease-Alzheimer's disease (AD) is a progressive neurodegenerative disorder characterized by progressive cognitive deterioration, usually starting with impaired memory recall (Jack \& Holtzman, 2013). The pathological hallmarks include $\beta$-amyloid plaques and hyperphosphorylated tau protein neurofibrillary tangles. AD is associated with increasing age and is the most common form of dementia in adults.

Alterations in the circadian system, particularly in the sleep/wake rhythm, have long been recognized in $\mathrm{AD}$. In healthy older adults, reduction in amplitude and later acrophase of the rest/activity rhythm predicts later risk of developing dementia (Tranah et al., 2011). In people with $\mathrm{AD}$, there is increased sleep fragmentation with increased activity at night (Bonanni et al., 2005; Jacobs, Ancoli-Israel, Parker, \& Kripke, 1989), accompanied by increased napping and decreased activity during the day (Bonanni et al., 2005; Witting, Kwa, Eikelenboom, Mirmiran, \& Swaab, 1990). Taken together, the amplitude of the rest/ activity rhythm dampens and eventually becomes arrhythmic, with equal amounts of sleep occurring during the day and night (Tractenberg, Singer, \& Kaye, 2006), a pattern typical of ISWRD (American Academy of Sleep Medicine, 2014). The degree of reduction in rest/ activity amplitude correlates with the severity of AD (Witting et al., 1990). Furthermore, decreased inter-daily stability of the rest/activity cycle correlates with the severity of cognitive impairment, functional and social impairment, apathy and depression (Carvalho- 
Bos, Riemersma-van der Lek, Waterhouse, Reilly, \& Van Someren, 2007; Kuhlmei, Walther, Becker, Muller, \& Nikolaus, 2013). As with PD, cause and effect remain unclear. While much of the data focuses on circadian dysregulation as a symptom of $\mathrm{AD}$, there is some evidence from fly models that circadian disruption through nocturnal light exposure results in increased tau deposition and neurodegeneration (Kim et al., 2018), so circadian dysregulation may serve to speed the progression of disease in vulnerable individuals.

Sundowning, another symptom frequently seen in $\mathrm{AD}$, is a period of agitation and disruptive behavior, typically occurring in the later afternoon and early evening, suggesting a circadian rhythm disturbance underlying this phenomenon. Those individuals with sundowning have less light exposure (Ancoli-Israel, Martin, et al., 2003), a later acrophase and lower amplitude of the core body temperature rhythm when compared to AD patients without sundowning (Volicer, Harper, Manning, Goldstein, \& Satlin, 2001). However, there is some data from nursing home residents suggesting that this agitation actually occurs throughout the day, and the apparent peak in evening symptoms reflects the greater impact on the evening staff rather than a greater magnitude of symptoms (Bliwise, Carroll, Lee, Nekich, \& Dement, 1993).

There are several postulated mechanisms for the circadian disruption observed in $\mathrm{AD}$, including alterations in zeitgeber input to the $\mathrm{SCN}$, changes to the $\mathrm{SCN}$ itself, and desynchrony of peripheral rhythms. In support of reduced input to the SCN in AD, several studies using wrist actigraphy including a luxometer to measure light exposure have demonstrated that people with AD have decreased total light exposure when compared to controls (Ancoli-Israel et al., 1997; Figueiro, Hamner, Higgins, Hornick, \& Rea, 2012; van Someren et al., 1996). People with AD may also have degeneration and amyloid deposition in retinal ganglion cells providing photic input to the SCN (Katz, Rimmer, Iragui, \& Katzman, 1989; La Morgia et al., 2016), as well as decreased cholinergic input to the SCN from the nucleus basalis of Meynert (NBM) a site of neurodegeneration in AD (Madeira, Pereira, Silva, Cadete-Leite, \& Paula-Barbosa, 2004). Finally, people with AD may have decreased social and physical activity, both of which are additional zeitbegers and may in turn lead to less light exposure. Some interventional studies with structured physical or social activity do appear to improve nighttime sleep, reduce daytime sleepiness, and advance the rest/activity rhythm acrophase (Deschenes \& McCurry, 2009).

Pathology at the level of the SCN may also lead to circadian changes in AD. Pathological studies have shown evidence of $\beta$-amyloid plaques and neurofibrillary tangles with atrophy and cell loss in the SCN (Hofman \& Swaab, 2006; Stopa et al., 1999; Swaab, Fliers, \& Partiman, 1985; Zhou, Hofman, \& Swaab, 1995). These changes are associated with decreased activity and core body temperature rhythm amplitude and activity fragmentation (Harper et al., 2008). In addition, there is a negative correlation between the number of VIP expressing neurons in the SCN and the amplitude of rest-activity patterns in patients with $\mathrm{AD}$ (Wang et al., 2015).

Downstream of the SCN, melatonin secretion is also affected. Melatonin secretion can decrease with healthy aging (Iguchi, Kato, \& Ibayashi, 1982; Skene \& Swaab, 2003), but in $\mathrm{AD}$ the amplitude of serum melatonin is further reduced, with an irregular peak (Liu, Zhou, 
van Heerikhuize, Hofman, \& Swaab, 1999; Mishima et al., 1999; Skene et al., 1990). Cerebrospinal fluid melatonin levels are also reduced in AD. This finding can be seen even in early pathological stages of the disease (Liu et al., 1999; Zhou, Liu, Kamphorst, Hofman, $\&$ Swaab, 2003) and correlates with the severity of neuropathology (Zhou et al., 2003). Although the mechanism of decline in melatonin in $\mathrm{AD}$ is not known, low melatonin may play a role in the pathophysiology of $\mathrm{AD}$. In animal models of $\mathrm{AD}$, melatonin inhibits $\beta$ amyloid aggregation and toxicity (Feng et al., 2004; Jang et al., 2005; Olcese et al., 2009; Poeggeler et al., 2001) and also inhibits tau hyperphosphorylation (Wang, Ling, Cao, Zhu, \& Wang, 2004). Furthermore, melatonin is a potent antioxidant which may reduce oxidative stress, inflammation, and cell death (Dragicevic et al., 2011; Olcese et al., 2009). In mouse models of $\mathrm{AD}$, melatonin administration reduces deterioration of learning and memory and inhibits amyloid deposition in the frontal cortex and hippocampus (Feng et al., 2004; Olcese et al., 2009).

Another potential mechanism of cognitive dysfunction in AD may be circadian desynchrony of rhythms in brain networks (Kyriacou \& Hastings, 2010). The hippocampus is a key area for memory formation and is a major site of neurodegeneration in AD. Long term potentiation - a form of synaptic plasticity that contributes to associative learning-exhibits circadian variation in the rat hippocampus, with an increase during the inactive state and a decrease during the active state (Harris \& Teyler, 1983; Stranahan, 2012). Furthermore, the hippocampus sends projections to the SCN, and hippocampal plasticity appears to be sensitive to constant light, circadian gene manipulation, and melatonin (Gorfine \& Zisapel, 2007; Moga \& Moore, 1997; Stranahan, 2012). The hippocampus and other brain regions have semi-autonomous clocks (Kyriacou \& Hastings, 2010), and circadian oscillations in different brain regions differ in rhythms and amplitude and their dependence on the SCN (Guilding \& Piggins, 2007). Perhaps circadian desynchrony between different brain regions could contribute to the cognitive impairment seen in $\mathrm{AD}$.

Recent and exciting data suggests that sleep is directly linked to $\beta$-amyloid accumulation. Data from a transgenic mouse model of $\mathrm{AD}$ demonstrates that $\beta$-amyloid has a diurnal rhythm, increasing during wakefulness and decreasing during sleep, with further increases following sleep deprivation (Kang et al., 2009). During sleep, toxic products such as $\beta$ amyloid are cleared from the brain (Xie et al., 2013). However, whether or not the accumulation and clearance of $\beta$-amyloid is influenced by the circadian system directly or indirectly by circadian control of the sleep/wake cycle remains unclear.

Several studies have examined the effect of administering exogenous melatonin in the elderly and individuals with dementia. Melatonin administration appears to improve sundowning (Fainstein, Bonetto, Brusco, \& Cardinali, 1997) and agitation (CohenMansfield, Garfinkel, \& Lipson, 2000), decrease nocturnal activity (Asayama et al., 2003; Mishima et al., 1999), and increase the daily amplitude of the rest/activity rhythm (JeanLouis, von Gizycki, \& Zizi, 1998). One study showed an increase in nocturnal sleep time (Asayama et al., 2003) though others did not. However, many of these studies have been small, uncontrolled and used different doses of melatonin (typically 3-6 mg). Furthermore, only two of these studies specifically examined people with $\mathrm{AD}$ as opposed to also including individuals with other types of dementia (Asayama et al., 2003; Mishima et al., 1999). A 
larger study of 157 people with AD did not confirm objective benefit by actigraphy, though there was a trend for increase in total sleep time and caregiver ratings of the participants' sleep quality demonstrated overall improvement (Singer et al., 2003).

Bright light therapy in individuals with AD has been evaluated in several small studies. Although there is no standardized intensity or duration of therapy among the reports, in general morning bright light therapy (usually $\geq 2,500$ lux) improves consolidation of the rest/ activity rhythm, increases nighttime sleep and daytime wakefulness, and improves evening agitation (Hanford \& Figueiro, 2013). Most studies of evening light exposure show improvement in consolidation of the rest/activity rhythm (Hanford \& Figueiro, 2013), and even 30 lux of blue light improves sleep efficiency (Figueiro \& Rea, 2005). Continuous daily light exposure increases total sleep time, improves inter-daily stability of the rest/activity rhythm, improves mood, and slightly attenuates cognitive deterioration when given long term (Hanford \& Figueiro, 2013; Riemersma-van der Lek et al., 2008). A 24 hr light/dark scheme has been proposed to improve the sleep/wake rhythm, decrease agitation, and reduce falls at night (Figueiro, 2008). This plan consists of high amount of light exposure during the day and low amount at night, good visual conditions when awake, and nightlights to reduce falls when awake at night.

\section{4 | ASSESSMENT OF CIRCADIAN RHYTHM DYSFUNCTION}

With the growing understanding of the role of circadian dysfunction across disease states, it is also important to have appropriate diagnostic tools to quantify circadian function/ dysfunction and to guide treatment timing. There are many techniques currently used to establish circadian timing, however as circadian science advances, additional strategies have the potential to be useful both for improved diagnosis, and better tailoring treatment strategies.

Current diagnosis of circadian rhythm disorders focuses on measurement of daily activity patterns using actigraphy, with consideration for inclusion of an additional circadian phase marker such as melatonin or cortisol. Actigraphy has been validated as a means of measuring sleep and wake (Ancoli-Israel, Cole, et al., 2003) and recently was demonstrated to be approximately $80 \%$ accurate in distinguishing sleep and wake when compared to polysomnography (PSG; Marino et al., 2013). Melatonin or cortisol can be measured in the plasma however this is often impractical in the outpatient setting, as samples need to be collected every 30-60 min through an indwelling venous catheter. As an alternative, melatonin can also be collected in the saliva, and has been validated as a comparable measure to plasma (Voultsios, Kennaway, \& Dawson, 1997). More recently it has been demonstrated that home salivary sampling can accurately determine a patient's dim-light melatonin onset (DLMO; Burgess, Wyatt, Park, \& Fogg, 2015). The timing of DLMO can be used both as a marker of circadian phase, but can also be used to assess response to treatment, discussed in the next section (Pandi-Perumal et al., 2007).

While the above measures are the current standards for testing in circadian disorders, there are several new techniques being developed that may be potentially useful. First, in addition to being secreted in the plasma and the saliva, the primary metabolite of melatonin 6- 
sulfatoxymelatonin (aMT6s) secreted in the urine and can also be measured as a marker of circadian timing. Urine samples can be collected at scheduled intervals over a $24-48 \mathrm{hr}$ period and provide an estimate of timing and amplitude of daily melatonin production (Benloucif et al., 2008). In some populations, obtaining urine samples may be simpler and more cost effective than frequent sampling of plasma or saliva.

Core body temperature is another marker of circadian timing however the standard method of collection, using an indwelling rectal thermometer is sometimes impractical or undesirable. Newer techniques are being developed, using a wrist mounted thermometer to measure the daily fluctuations in temperature. Core body temperature normally falls as an individual is falling asleep, reaching a nadir, and then rises $\sim 2 \mathrm{hr}$ prior to waking. Skin temperature, on the other hand, begins to increase prior to bedtime, reflecting the dissipation of core heat, and drops just after awakening (Sarabia, Rol, Mendiola, \& Madrid, 2008). Validation studies have shown good correlation between the evening temperature increase measured at the wrist and DLMO suggesting that this may be another, less invasive means of measuring circadian timing (Bonmati-Carrion et al., 2013).

One of the limitations of many current sampling strategies is the fact that samples are only predictive when compared to data obtained during the hours or days preceding and following a particular sample. For example, a single melatonin sample is unlikely to be able to accurately predict circadian timing, as it is necessary to determine the precise time point that it starts to rise, which requires sampling over a $4-5 \mathrm{hr}$ time window, at a minimum. As a result, the goal is to find a biomarker that can be predictive of circadian time, using just a single or limited number of samples. Current studies have demonstrated that it is possible to create either a molecular (Ueda et al., 2004) or metabolic (Minami et al., 2009) timetable, by looking at the rhythmic expression of several genes or metabolites over time. After constructing a standard profile with a select set of genes or metabolites, one can compare the observed profile in a sample with the standard timetable to determine predicted time. Studies are ongoing to validate this approach in human studies (Kasukawa et al., 2012) and to develop a practical means of conducting this testing in the clinical setting (Wittenbrink et al., 2018).

Finally, another component of circadian rhythms that is potentially important to measure intrinsic period of an individual, or tau, as this may contribute to the underlying pathophysiology of many circadian disorders. Tau is often shorter in individuals with ASWPD, while it is longer in individuals with DSWPD or N24SWD. Determining an individual's tau can provide insight both into the underlying pathophysiology of the disorder, as well as help guide treatment. Historically, the best way to measure the intrinsic period of an individual was to use a forced desynchrony protocol, in which individuals are either placed in a 20 or $28 \mathrm{~h}$ day to separate the sleep-wake rhythm from the circadian rhythm. However these protocols are both labor intensive and costly, making them impractical in the outpatient clinical setting. One potential solution to this problem comes from recent studies that have been able to obtain isolated cell cultures from individual patients, and using reporter clock genes, measure the individual's circadian period in a dish. Fibroblasts can be isolated and cultured from a small skin punch biopsy, infected with a lentivirus containing a Bmal1-luciferase reporter construct, and monitored over time (Brown 
et al., 2008). Using this technique, it has been demonstrated that morning types have a shorter biologic period than evening-types (Brown et al., 2008). This period measurement has also been shown to correlate with the period obtained from daily melatonin sampling in blind individuals (Pagani et al., 2010). As other peripheral tissues also contain clock genes, this also could be applied to other samples, such as monocytes from a blood sample, which have also been demonstrated to exhibit rhythmicity (Druzd \& Scheiermann, 2013) or from hair follicle (Watanabe et al., 2012). Clinically one could imagine taking a small skin, blood or hair sample from a patient, and easily being able to characterize their individual circadian phenotype.

As we will review in the next section, having an accurate and easily obtained measure of circadian timing can be very important for determining the appropriate timing for circadian based interventions.

\section{5 | CHRONOTHERAPY}

An understanding of circadian biology is important for personalized and precision medicine. One of the best studied of these areas is the use of specific timing of medication administration for the treatment of cancer, often referred to as chronotherapy. Even when administered continuously, chemotherapeutic agents exhibit a circadian pattern in everything from the metabolism of the drug and the toxicity of the agent on healthy tissues to the responsiveness of the target enzyme to the chemotherapeutic agent. By taking all of these factors into account, it is possible to time the administration of the medication to occur during a period where the efficacy will be highest, while the risk for toxicity to healthy tissues will be lowest (Innominato, Levi, \& Bjarnason, 2010). The individual timing for each chemotherapeutic agent is different; however, knowledge of these properties has resulted in increased attention to the timing of drug administration in clinical trials, with improved patient outcomes.

There is some evidence in other areas of medicine beyond oncology that the timing of medication administration can have significant impact on the efficacy of treatment. A recent analysis of RNA expression profiles in mice demonstrated that $43 \%$ of protein coding genes were rhythmic, and the majority of commonly prescribed medications target one of these rhythmic genes, suggesting that time of dosing of medications may be important in the optimal treatment of many health conditions (Zhang, Lahens, Ballance, Hughes, \& Hogenesch, 2014). For example, blood pressure is known to have a circadian pattern, typically exhibiting a nocturnal dip in the middle of the night. For that reason, many of the studies looking at the role of chronotherapy in medical treatment have looked at the timing of anti-hypertensives. A recent meta-analysis summarizes the results of these studies, which generally have found that bedtime administration of medications improves outcomes, presumably by restoring the physiological dip in blood pressure that is usually seen (Kaur, Phillips, Wong, \& Saini, 2013). This same treatment strategy has been examined in patients with chronic kidney disease thought to be secondary to hypertension, and in these individuals nocturnal administration of antihypertensives has proven to be more beneficial (Hermida et al., 2013). Similarly, it has been found that in women with pre-eclampsia, administration of aspirin at bedtime but not on awakening improved outcomes (Ayala, 
Ucieda, \& Hermida, 2013). While there are few human trials to date, a recent review also highlighted the potential role for chronotherapy in the treatment of epilepsy (Ramgopal, Thome-Souza, \& Loddenkemper, 2013). Finally, there is also research currently underway into the formulation of timed release capsule to be used as chronotherapy for individuals with nocturnal asthma (Ranjan et al., 2013).

Other circadian based treatment options are also available, beyond the timing of medication administration. As an example, light is one of the primary regulators of the circadian clock. Light in the evening, prior to the core body temperature minimum, causes phase delays, while light in the morning, after the core body temperature minimum, causes phase advances (Khalsa, Jewett, Cajochen, \& Czeisler, 2003). While light can be used to adjust timing for the primary CRSWD, light can also be used as an adjunctive treatment for many other medical disorders. For example, there is evidence that scheduled bright light exposure can improve subjective outcomes during chemotherapy. It has been demonstrated that women with breast cancer show significant circadian disruption, even prior to the onset of chemotherapy (Liu et al., 2013). Early morning bright light therapy has been shown to protect against this disruption, which may also serve to protect against cancer-related fatigue (Ancoli-Israel et al., 2012; Neikrug et al., 2012). These findings have been replicated in patients with other types of cancer besides breast cancer (Johnson et al., 2018; Wu et al., 2018).

Within the intensive care unit (ICU) environment a focus on increasing daytime light exposure may also be a beneficial consideration. A recent observational study demonstrated that the $24 \mathrm{hr}$ light exposure pattern of patients in the ICU exhibited an overall low amplitude, with light intensity never exceeding 150 lux (Fan, Abbott, Reid, Zee, \& Maas, 2017). Future studies are needed to determine whether increasing bright light exposure during the day may improve patient outcomes.

Melatonin can also be used to help reset the circadian clock. When given approximately $5 \mathrm{hr}$ before DLMO, exogenous melatonin has been demonstrated to advance the circadian clock, while melatonin in the early morning can delay the circadian clock (Nagtegaal, Kerkhof, Smits, Swart, \& Van Der Meer, 1998).

In addition to light and melatonin, there are many other time cues that can also reset the circadian clock that could potentially be used in the treatment of CRSWDs. In rodent studies, it has long been appreciated that signals including dark pulses, sleep deprivation or forced activity during the inactive period, referred to as "non-photic cues", can serve as resetting signals for the circadian clock directly (Challet, Turek, Laute, \& Van Reeth, 2001; Reebs \& Mrosovsky, 1989) or by modulating the effects of light (Yannielli \& Harrington, 2004). Furthermore, these signals are thought to be transmitted by serotonergic signals from the MR (Bobrzynska, Godfrey, \& Mrosovsky, 1996). More recently, it has been demonstrated in rodents that perinatal exposure to fluoxetine, a selective serotonin reuptake inhibitor (SSRI), resulted in a shorter free-running period and larger light induced phase advances (Kiryanova, Smith, Dyck, \& Antle, 2013). Given the large number of individuals currently taking SSRIs, this work could potentially have large implications for the circadian health of the population as a whole. 
While research examining the role of non-photic cues in human circadian resetting is limited, there are a handful of experiments to date. Physical exercise in the evening, around the habitual sleep time, has been shown to produce significant phase delays (Barger, Wright, Hughes, \& Czeisler, 2004; Dijk \& Czeisler, 1994). Exercise in the morning, on the other hand has been shown to accelerate phase advances (Miyazaki, Hashimoto, Masubuchi, Honma, \& Honma, 2001). This suggests there may be some benefit to focusing on these non-photic cues as potential treatment strategies, either as adjunctive therapy for individuals who are not receiving full benefits from a combination of light and melatonin, or as an alternative strategy for individuals who are unable to tolerate light and/or melatonin.

The timing and pattern of food intake can also serve as an important zeitgeber. There are circadian rhythms to metabolic processes, such as glucose metabolism, and animal studies have demonstrated that restricting feeding opportunities during the active period results in a decrease in cholesterol, increase in insulin sensitivity (Hatori et al., 2012), improvement in sleep quality (Alvarenga, Andersen, Papale, Antunes, \& Tufik, 2005), and a decrease in age related decline in cardiac function (Gill, Le, Melkani, \& Panda, 2015). Human studies are more limited, but a small observational study in humans demonstrated that restricting feeding to a 10-12 hr window resulted in a decrease in body weight and an improvement in sleep quality (Gill \& Panda, 2015). A more recent study demonstrated that restricting feeding to an $8 \mathrm{hr}$ window during the daytime, for 12 weeks, was associated with a significant decrease in body weight and systolic blood pressure when compared to controls (Gabel et al., 2018). In addition, time restricted feeding has recently been demonstrated to improve locomotor activity and sleep in a mouse model of the neurodegenerative disorder Huntington's disease (Wang et al., 2018). Studies are ongoing to determine whether time restricted feeding may be beneficial to improving circadian amplitude and cardiometabolic health in humans.

\section{6| CONCLUSIONS}

As has been illustrated in this review, circadian rhythms are an important component of nearly all aspects of physiology, extending far beyond simple regulation of the timing of the sleep-wake cycle. This is a rapidly growing field, with many potential areas for new research. On one end of the spectrum, knowledge of circadian rhythms can be utilized to augment and improve the efficacy of medical treatments. At the other end of the spectrum, circadian disruption appears to play an important role in many medical disorders, either as an early symptom as is seen in neurodegenerative disorders, or possibly even as a causative factor, as is seen in the multiple comorbid disorders seen in shift workers and individuals with social jet leg. All of this argues for the importance of a focus on circadian health as an essential component of both disease treatment and prevention. With that in mind, we propose the development of a new field of medicine to focus precisely on these complex issues: circadian medicine.

\section{Abbreviations:}
AD
Alzheimer('s disease 
ASWPD advanced sleep wake phase disorder

CRSWDs circadian rhythm sleep wake disorders

DLMO dim-light melatonin onset

DSWPD delayed sleep wake phase disorder

ISWRD irregular sleep wake rhythm disorder

N24SWD non-24 hr sleep wake disorder

NHS Nurses' Health Study

PD Parkinson's disease

PSG polysomnography

SCN suprachiasmatic nucleus

\section{REFERENCES}

Abbott SM, \& Zee PC (2015). Irregular sleep-wake rhythm disorder. Sleep Medicine Clinics, 10, $517-$ 522. 10.1016/j.jsmc.2015.08.005 [PubMed: 26568126]

Alvarenga TA, Andersen ML, Papale LA, Antunes IB, \& Tufik S (2005). Influence of long-term food restriction on sleep pattern in male rats. Brain Research, 1057, 49-56. 10.1016/ j.brainres.2005.07.024 [PubMed: 16122716]

American Academy of Sleep Medicine (2005). The international classification of sleep disorders: Diagnostic and coding manual. Westchester, IL: American Academy of Sleep Medicine.

American Academy of Sleep Medicine (2014). International classification of sleep disorders. Darien, IL: American Academy of Sleep Medicine.

Ancoli-Israel S, Cole R, Alessi C, Chambers M, Moorcroft W, \& Pollak CP (2003). The role of actigraphy in the study of sleep and circadian rhythms. Sleep, 26, 342-392. 10.1093/sleep/26.3.342 [PubMed: 12749557]

Ancoli-Israel S, Klauber MR, Jones DW, Kripke DF, Martin J, Mason W, ... Fell R (1997). Variations in circadian rhythms of activity, sleep, and light exposure related to dementia in nursing-home patients. Sleep, 20, 18-23. [PubMed: 9130329]

Ancoli-Israel S, Martin JL, Gehrman P, Shochat T, Corey-Bloom J, Marler M, ... Levi L (2003). Effect of light on agitation in institutionalized patients with severe Alzheimer disease. American Journal of Geriatric Psychiatry, 11, 194-203. 10.1097/00019442-200303000-00010 [PubMed: 12611749]

Ancoli-Israel S, Rissling M, Neikrug A, Trofimenko V, Natarajan L, Parker BA, ... Liu L (2012). Light treatment prevents fatigue in women undergoing chemotherapy for breast cancer. Supportive Care in Cancer, 20, 1211-1219. 10.1007/s00520-011-1203-z [PubMed: 21660669]

Aoki H, Ozeki Y, \& Yamada N (2001). Hypersensitivity of melatonin suppression in response to light in patients with delayed sleep phase syndrome. Chronobiology International, 18, 263-271. 10.1081/ CBI-100103190 [PubMed: 11379666]

Asayama K, Yamadera H, Ito T, Suzuki H, Kudo Y, \& Endo S (2003). Double blind study of melatonin effects on the sleep-wake rhythm, cognitive and non-cognitive functions in Alzheimer type dementia. Journal of Nippon Medical School, 70, 334-341. 10.1272/jnms.70.334 [PubMed: 12928714]

Ayala DE, Ucieda R, \& Hermida RC (2013). Chronotherapy with low-dose aspirin for prevention of complications in pregnancy. Chronobiology International, 30, 260-279.

10.3109/07420528.2012.717455 [PubMed: 23004922] 
Barclay JL, Husse J, Bode B, Naujokat N, Meyer-Kovac J, Schmid SM, ... Oster H (2012). Circadian desynchrony promotes metabolic disruption in a mouse model of shiftwork. PLoS One, 7, e37150 10.1371/journal.pone.0037150 [PubMed: 22629359]

Barger LK, Wright KP Jr, Hughes RJ, \& Czeisler CA (2004). Daily exercise facilitates phase delays of circadian melatonin rhythm in very dim light. American Journal of Physiology. Regulatory, Integrative and Comparative Physiology, 286, R1077-R1084. 10.1152/ajpregu.00397.2003

Baron KG, Reid KJ, Wolfe LF, Attarian H, \& Zee PC (2018). Phase relationship between DLMO and sleep onset and the risk of metabolic disease among normal weight and overweight/obese adults. Journal of Biological Rhythms, 33, 76-83. 10.1177/0748730417745914 [PubMed: 29262758]

Benloucif S, Burgess HJ, Klerman EB, Lewy AJ, Middleton B, Murphy PJ, ... Revell VL (2008). Measuring melatonin in humans. Journal of Clinical Sleep Medicine, 4, 66-69. [PubMed: 18350967]

Bliwise DL, Carroll JS, Lee KA, Nekich JC, \& Dement WC (1993). Sleep and "sundowning" in nursing home patients with dementia. Psychiatry Research, 48, 277-292. 10.1016/0165-1781(93)90078-U [PubMed: 8272449]

Bobrzynska KJ, Godfrey MH, \& Mrosovsky N (1996). Serotonergic stimulation and nonphotic phaseshifting in hamsters. Physiology \& Behavior, 59, 221-230. 10.1016/0031-9384(95)02130-2 [PubMed: 8838598]

Bonanni E, Maestri M, Tognoni G, Fabbrini M, Nucciarone B, Manca ML, ... Murri L (2005). Daytime sleepiness in mild and moderate Alzheimer's disease and its relationship with cognitive impairment. Journal of Sleep Research, 14, 311-317. 10.1111/j.1365-2869.2005.00462.x [PubMed: 16120107]

Bonmati-Carrion MA, Middleton B, Revell V, Skene DJ, Rol MA, \& Madrid JA (2013). Circadian phase asessment by ambulatory monitoring in humans: Correlation with dim light melatonin onset. Chronobiology International, 31, 37-51. [PubMed: 24164100]

Bordet R, Devos D, Brique S, Touitou Y, Guieu JD, Libersa C, \& Destee A (2003). Study of circadian melatonin secretion pattern at different stages of Parkinson's disease. Clinical Neuropharmacology, 26, 65-72. 10.1097/00002826-200303000-00005 [PubMed: 12671525]

Breen DP, Nombela C, Vuono R, Jones PS, Fisher K, Burn DJ, ... Barker RA (2016). Hypothalamic volume loss is associated with reduced melatonin output in Parkinson's disease. Movement Disorders, 31, 1062-1066. 10.1002/mds.26592 [PubMed: 26971528]

Brown DL, Feskanich D, Sanchez BN, Rexrode KM, Schernhammer ES, \& Lisabeth LD (2009). Rotating night shift work and the risk of ischemic stroke. American Journal of Epidemiology, 169, 1370-1377. 10.1093/aje/kwp056 [PubMed: 19357324]

Brown SA, Kunz D, Dumas A, Westermark PO, Vanselow K, Tilmann-Wahnschaffe A, ... Kramer A (2008). Molecular insights into human daily behavior. Proceedings of the National Academy of Sciences of the United States of America, 105, 1602-1607. 10.1073/pnas.0707772105 [PubMed: 18227513]

Brown MA, Quan SF, \& Eichling PS (2011). Circadian rhythm sleep disorder, free-running type in a sighted male with severe depression, anxiety, and agoraphobia. Journal of Clinical Sleep Medicine, 7, 93-94. [PubMed: 21344043]

Burgess HJ, Wyatt JK, Park M, \& Fogg LF (2015). Home circadian phase assessments with measures of compliance yield accurate dim light melatonin onsets. Sleep, 38, 889-897. [PubMed: 25409110]

Campbell SS, \& Murphy PJ (2007). Delayed sleep phase disorder in temporal isolation. Sleep, 30, 1225-1228. 10.1093/sleep/30.9.1225 [PubMed: 17910395]

Cardinali DP, Pagano ES, Scacchi Bernasconi PA, Reynoso R, \& Scacchi P (2013). Melatonin and mitochondrial dysfunction in the central nervous system. Hormones and Behavior, 63, 322-330. 10.1016/j.yhbeh.2012.02.020 [PubMed: 22391273]

Carvalho-Bos SS, Riemersma-van der Lek RF, Waterhouse J, Reilly T, \& Van Someren EJ (2007). Strong association of the rest-activity rhythm with well-being in demented elderly women. American Journal of Geriatric Psychiatry, 15, 92-100. 10.1097/01.JGP.0000236584.03432.dc [PubMed: 17272729] 
Challet E, Turek FW, Laute M, \& Van Reeth O (2001). Sleep deprivation decreases phase-shift responses of circadian rhythms to light in the mouse: Role of serotonergic and metabolic signals. Brain Research, 909, 81-91. 10.1016/S0006-8993(01)02625-7 [PubMed: 11478924]

Cheung IN, Zee PC, Shalman D, Malkani RG, Kang J, \& Reid KJ (2016). Morning and evening blueenriched light exposure alters metabolic function in normal weight adults. PLoS One, 11, e0155601 10.1371/journal.pone.0155601 [PubMed: 27191727]

Cohen-Mansfield J, Garfinkel D, \& Lipson S (2000). Melatonin for treatment of sundowning in elderly persons with dementia - A preliminary study. Archives of Gerontology and Geriatrics, 31, 65-76. 10.1016/S0167-4943(00)00068-6 [PubMed: 10989165]

Colligan MJ, \& Rosa RR (1990). Shiftwork effects on social and family life. Occupational Medicine, 5, 315-322. [PubMed: 2203160]

Davis S, Mirick DK, \& Stevens RG (2001). Night shift work, light at night, and risk of breast cancer. Journal of the National Cancer Institute, 93, 1557-1562. 10.1093/jnci/93.20.1557 [PubMed: 11604479]

Deschenes CL, \& McCurry SM (2009). Current treatments for sleep disturbances in individuals with dementia. Current Psychiatry Reports, 11, 20-26. 10.1007/s11920-009-0004-2 [PubMed: 19187704]

Dibner C, \& Schibler U (2015). Circadian timing of metabolism in animal models and humans. Journal of Internal Medicine, 277, 513-527. 10.1111/joim.12347 [PubMed: 25599827]

Dijk DJ, \& Czeisler CA (1994). Paradoxical timing of the circadian rhythm of sleep propensity serves to consolidate sleep and wakefulness in humans. Neuroscience Letters, 166, 63-68. 10.1016/0304-3940(94)90841-9 [PubMed: 8190360]

Dowling GA, Mastick J, Colling E, Carter JH, Singer CM, \& Aminoff MJ (2005). Melatonin for sleep disturbances in Parkinson's disease. Sleep Medicine, 6, 459-466. 10.1016/j.sleep.2005.04.004 [PubMed: 16084125]

Dragicevic N, Copes N, O’Neal-Moffitt G, Jin J, Buzzeo R, Mamcarz M, ... Bradshaw PC (2011). Melatonin treatment restores mitochondrial function in Alzheimer's mice: A mitochondrial protective role of melatonin membrane receptor signaling. Journal of Pineal Research, 51, 75-86. 10.1111/j.1600-079X.2011.00864.x [PubMed: 21355879]

Druzd D, \& Scheiermann C (2013). Immunology. Some monocytes got rhythm. Science, 341, 1462 1464. 10.1126/science.1244445 [PubMed: 24072913]

Facco FL, Grobman WA, Reid KJ, Parker CB, Hunter SM, Silver RM, ... Zee PC (2017). Objectively measured short sleep duration and later sleep midpoint in pregnancy are associated with a higher risk of gestational diabetes. American Journal of Obstetrics and Gynecology, 217, 447 e441-447 e413. [PubMed: 28599896]

Fainstein I, Bonetto AJ, Brusco LI, \& Cardinali DP (1997). Effects of melatonin in elderly patients with sleep disturbance: A pilot study. Current Therapeutic Research, 58, 990-1000. 10.1016/ S0011-393X(97)80066-5

Fan EP, Abbott SM, Reid KJ, Zee PC, \& Maas MB (2017). Abnormal environmental light exposure in the intensive care environment. Journal of Critical Care, 40, 11-14. 10.1016/j.jcrc.2017.03.002 [PubMed: 28292665]

Feng Z, Chang Y, Cheng Y, Zhang BL, Qu ZW, Qin C, \& Zhang JT (2004). Melatonin alleviates behavioral deficits associated with apoptosis and cholinergic system dysfunction in the APP 695 transgenic mouse model of Alzheimer's disease. Journal of Pineal Research, 37, 129-136. 10.1111/j.1600-079X.2004.00144.x [PubMed: 15298672]

Fertl E, Auff E, Doppelbauer A, \& Waldhauser F (1993). Circadian secretion pattern of melatonin in de novo parkinsonian patients: Evidence for phase-shifting properties of 1-dopa. Journal of Neural Transmission/Parkinson's Disease and Dementia Section, 5, 227-234. 10.1007/BF02257677

Figueiro M (2008). A proposed $24 \mathrm{~h}$ lighting scheme for older adults. Lighting Research and Technology, 40, 153-160. 10.1177/1477153507087299

Figueiro MG, Hamner R, Higgins P, Hornick T, \& Rea MS (2012). Field measurements of light exposures and circadian disruption in two populations of older adults. Journal of Alzheimer's Disease, 31, 711-715. 10.3233/JAD-2012-120484 
Figueiro M, \& Rea M (2005). LEDs: Improving the sleep quality of older adults. In Proceedings of the CIE Midterm Meeting and International Lighting Congress (pp. 18-21).

Flynn-Evans EE, Tabandeh H, Skene DJ, \& Lockley SW (2014). Circadian rhythm disorders and melatonin production in 127 blind women with and without light perception. Journal of Biological Rhythms, 29, 215-224. 10.1177/0748730414536852 [PubMed: 24916394]

Forman JP, Curhan GC, \& Schernhammer ES (2010). Urinary melatonin and risk of incident hypertension among young women. Journal of Hypertension, 28, 446-451. 10.1097/ HJH.0b013e3283340c16 [PubMed: 20090558]

Gabel K, Hoddy KK, Haggerty N, Song J, Kroeger CM, Trepanowski JF, ... Varady KA (2018). Effects of 8-hour time restricted feeding on body weight and metabolic disease risk factors in obese adults: A pilot study. Nutrition and Healthy Aging, 4, 345-353. 10.3233/NHA-170036 [PubMed: 29951594]

Gill S, Le HD, Melkani GC, \& Panda S (2015). Time-restricted feeding attenuates age-related cardiac decline in Drosophila. Science, 347, 1265-1269. 10.1126/science.1256682 [PubMed: 25766238]

Gill S, \& Panda S (2015). A smartphone app reveals erratic diurnal eating patterns in humans that can be modulated for health benefits. Cell Metabolism, 22, 789-798. 10.1016/j.cmet.2015.09.005 [PubMed: 26411343]

Gorfine T, \& Zisapel N (2007). Melatonin and the human hippocampus, a time dependent interplay. Journal of Pineal Research, 43, 80-86. 10.1111/j.1600-079X.2007.00446.x [PubMed: 17614839]

Guilding C, \& Piggins HD (2007). Challenging the omnipotence of the suprachiasmatic timekeeper: Are circadian oscillators present throughout the mammalian brain? European Journal of Neuroscience, 25, 3195-3216. 10.1111/j.1460-9568.2007.05581.x [PubMed: 17552989]

Hampp G, \& Albrecht U (2008). The circadian clock and mood-related behavior. Communicative and Integrative Biology, 1, 1-3. 10.4161/cib.1.1.6286 [PubMed: 19704445]

Hanford N, \& Figueiro M (2013). Light therapy and Alzheimer's disease and related dementia: Past, present, and future. Journal of Alzheimer's Disease, 33, 913-922. 10.3233/JAD-2012-121645

Hansen J, \& Lassen CF (2012). Nested case-control study of night shift work and breast cancer risk among women in the Danish military. Occupational and Environmental Medicine, 69, 551-556. 10.1136/oemed-2011-100240 [PubMed: 22645325]

Hansen AB, Stayner L, Hansen J, \& Andersen ZJ (2016). Night shift work and incidence of diabetes in the Danish Nurse Cohort. Occupational and Environmental Medicine, 73, 262-268. 10.1136/ oemed-2015-103342 [PubMed: 26889020]

Harper DG, Stopa EG, Kuo-Leblanc V, McKee AC, Asayama K, Volicer L, ... Satlin A (2008). Dorsomedial SCN neuronal subpopulations subserve different functions in human dementia. Brain, 131, 1609-1617. 10.1093/brain/awn049 [PubMed: 18372313]

Harris KM, \& Teyler TJ (1983). Age differences in a circadian influence on hippocampal LTP. Brain Research, 261, 69-73. 10.1016/0006-8993(83)91284-2 [PubMed: 6301629]

Hartmann A, Veldhuis JD, Deuschle M, Standhardt H, \& Heuser I (1997). Twenty-four hour cortisol release profiles in patients with Alzheimer's and Parkinson's disease compared to normal controls: Ultradian secretory pulsatility and diurnal variation. Neurobiology of Aging, 18, 285-289. 10.1016/S0197-4580(97)80309-0 [PubMed: 9263193]

Hatori M, Vollmers C, Zarrinpar A, DiTacchio L, Bushong EA, Gill S, ... Panda S (2012). Timerestricted feeding without reducing caloric intake prevents metabolic diseases in mice fed a highfat diet. Cell Metabolism, 15, 848-860. 10.1016/j.cmet.2012.04.019 [PubMed: 22608008]

Hermida RC, Smolensky MH, Ayala DE, Fernandez JR, Moya A, Crespo JJ, ... Portaluppi F (2013). Abnormalities in chronic kidney disease of ambulatory blood pressure $24 \mathrm{~h}$ patterning and normalization by bedtime hypertension chronotherapy. Nephrology, Dialysis, Transplantation, 29, 1160-1167.

van Hilten B, Hoff JI, Middelkoop HA, van der Velde EA, Kerkhof GA, Wauquier A, ... Roos RA (1994). Sleep disruption in Parkinson's disease. Assessment by continuous activity monitoring. Archives of Neurology, 51, 922-928. 10.1001/archneur.1994.00540210094018 [PubMed: 8080393] 
Hirano A, Shi G, Jones CR, Lipzen A, Pennacchio LA, Xu Y, ... Fu YH (2016). A Cryptochrome 2 mutation yields advanced sleep phase in humans. Elife, 5, e16695 10.7554/eLife.16695 [PubMed: 27529127]

Hofman MA, \& Swaab DF (2006). Living by the clock: The circadian pacemaker in older people. Ageing Research Reviews, 5, 33-51. 10.1016/j.arr.2005.07.001 [PubMed: 16126012]

Iguchi H, Kato KI, \& Ibayashi H (1982). Age-dependent reduction in serum melatonin concentrations in healthy human subjects. The Journal of Clinical Endocrinology and Metabolism, 55, 27-29. 10.1210/jcem-55-1-27 [PubMed: 7200489]

Innominato PF, Levi FA, \& Bjarnason GA (2010). Chronotherapy and the molecular clock: Clinical implications in oncology. Advanced Drug Delivery Reviews, 62, 979-1001. 10.1016/ j.addr.2010.06.002 [PubMed: 20600409]

Jack CR Jr, \& Holtzman DM (2013). Biomarker modeling of Alzheimer's disease. Neuron, 80, 13471358. 10.1016/j.neuron.2013.12.003 [PubMed: 24360540]

Jacobs D, Ancoli-Israel S, Parker L, \& Kripke DF (1989). Twenty-four-hour sleep-wake patterns in a nursing home population. Psychology and Aging, 4, 352-356. 10.1037/0882-7974.4.3.352 [PubMed: 2803629]

Jang MH, Jung SB, Lee MH, Kim CJ, Oh YT, Kang I, ... Kim EH (2005). Melatonin attenuates amyloid beta25-35-induced apoptosis in mouse microglial BV2 cells. Neuroscience Letters, 380, 26-31. 10.1016/j.neulet.2005.01.003 [PubMed: 15854745]

Jean-Louis G, von Gizycki H, \& Zizi F (1998). Melatonin effects on sleep, mood, and cognition in elderly with mild cognitive impairment. Journal of Pineal Research, 25, 177-183. 10.1111/ j.1600-079X.1998.tb00557.x [PubMed: 9745987]

Johnson JA, Garland SN, Carlson LE, Savard J, Simpson JSA, Ancoli-Israel S, \& Campbell TS (2018). Bright light therapy improves cancer-related fatigue in cancer survivors: A randomized controlled trial. Journal of Cancer Survivorship, 12, 206-215. 10.1007/s11764-017-0659-3 [PubMed: 29127575]

Kang JE, Lim MM, Bateman RJ, Lee JJ, Smyth LP, Cirrito JR, ... Holtzman DM (2009). Amyloidbeta dynamics are regulated by orexin and the sleep-wake cycle. Science, 326, 1005-1007. 10.1126/science.1180962 [PubMed: 19779148]

Karlsson B, Knutsson A, \& Lindahl B (2001). Is there an association between shift work and having a metabolic syndrome? Results from a population based study of 27,485 people. Occupational and Environmental Medicine, 58, 747-752. 10.1136/oem.58.11.747 [PubMed: 11600731]

Kasukawa T, Sugimoto M, Hida A, Minami Y, Mori M, Honma S, ... Ueda HR (2012). Human blood metabolite timetable indicates internal body time. Proceedings of the National Academy of Sciences of the United States of America, 109, 15036-15041. 10.1073/pnas.1207768109 [PubMed: 22927403]

Katz B, Rimmer S, Iragui V, \& Katzman R (1989). Abnormal pattern electroretinogram in Alzheimer's disease: Evidence for retinal ganglion cell degeneration? Annals of Neurology, 26, 221-225. 10.1002/(ISSN)1531-8249 [PubMed: 2774509]

Kaur G, Phillips C, Wong K, \& Saini B (2013). Timing is important in medication administration: A timely review of chronotherapy research. International Journal of Clinical Pharmacy, 35, 344-358. 10.1007/s11096-013-9749-0 [PubMed: 23329340]

Khalsa SB, Jewett ME, Cajochen C, \& Czeisler CA (2003). A phase response curve to single bright light pulses in human subjects. The Journal of Physiology, 549, 945-952. 10.1113/ jphysiol.2003.040477 [PubMed: 12717008]

Kim M, Subramanian M, Cho YH, Kim GH, Lee E, \& Park JJ (2018). Short-term exposure to dim light at night disrupts rhythmic behaviors and causes neurodegeneration in fly models of tauopathy and Alzheimer's disease. Biochemical and Biophysical Research Communications, 495, 17221729. 10.1016/j.bbrc.2017.12.021 [PubMed: 29217196]

Kiryanova V, Smith VM, Dyck RH, \& Antle MC (2013). The effects of perinatal fluoxetine treatment on the circadian system of the adult mouse. Psychopharmacology (Berl), 225, 743-751. 10.1007/ s00213-012-2861-3 [PubMed: 22972413] 
Kitamura S, Hida A, Enomoto M, Watanabe M, Katayose Y, Nozaki K, ... Mishima K (2012). Intrinsic circadian period of sighted patients with circadian rhythm sleep disorder, free-running type. Biological Psychiatry, 73, 63-69. [PubMed: 22846439]

Knutson KL, Wu D, Patel SR, Loredo JS, Redline S, Cai J, ... Zee PC (2017). Association between sleep timing, obesity, diabetes: The Hispanic Community Health Study/Study of Latinos (HCHS/ SOL) cohort study. Sleep, 40, zsx014If.

Kripke DF, Rex KM, Ancoli-Israel S, Nievergelt CM, Klimecki W, \& Kelsoe JR (2008). Delayed sleep phase cases and controls. Journal of Circadian Rhythms, 6, 6 10.1186/1740-3391-6-6 [PubMed: 18445295]

Kudo T, Loh DH, Truong D, Wu Y, \& Colwell CS (2011). Circadian dysfunction in a mouse model of Parkinson's disease. Experimental Neurology, 232, 66-75. 10.1016/j.expneurol.2011.08.003 [PubMed: 21864527]

Kuhlmei A, Walther B, Becker T, Muller U, \& Nikolaus T (2013). Actigraphic daytime activity is reduced in patients with cognitive impairment and apathy. European Psychiatry, 28, 94-97. 10.1016/j.eurpsy.2011.04.006 [PubMed: 21696925]

Kuzniar TJ, Kovacevic-Ristanovic R, Nierodzik CL, \& Smith LC (2012). Free-running (non-entrained to 24-h period) circadian sleep disorder in a patient with obstructive sleep apnea, delayed sleep phase tendency, and lack of social interaction. Sleep \& Breathing, 16, 313-315. 10.1007/ s11325-011-0535-8 [PubMed: 21594679]

Kyriacou CP, \& Hastings MH (2010). Circadian clocks: Genes, sleep, and cognition. Trends in Cognitive Sciences, 14, 259-267. 10.1016/j.tics.2010.03.007 [PubMed: 20418150]

La Morgia C, Ross-Cisneros FN, Koronyo Y, Hannibal J, Gallassi R, Cantalupo G, ... Carelli V (2016). Melanopsin retinal ganglion cell loss in Alzheimer disease. Annals of Neurology, 79, 90109. 10.1002/ana.24548 [PubMed: 26505992]

Lauretti E, Di Meco A, Merali S, \& Pratico D (2017). Circadian rhythm dysfunction: A novel environmental risk factor for Parkinson's disease. Molecular Psychiatry, 22, 280-286. 10.1038/ mp.2016.47 [PubMed: 27046648]

Lie JA, Roessink J, \& Kjaerheim K (2006). Breast cancer and night work among Norwegian nurses. Cancer Causes \& Control: CCC, 17, 39-44. 10.1007/s10552-005-3639-2

Liu L, Rissling M, Neikrug A, Fiorentino L, Natarajan L, Faierman M, ... Ancoli-Israel S (2013). Fatigue and circadian activity rhythms in breast cancer patients before and after chemotherapy: A controlled study. Fatigue, 1, 12-26. [PubMed: 23412418]

Liu RY, Zhou JN, van Heerikhuize J, Hofman MA, \& Swaab DF (1999). Decreased melatonin levels in postmortem cerebrospinal fluid in relation to aging, Alzheimer's disease, and apolipoprotein Eepsilon4/4 genotype. The Journal of Clinical Endocrinology and Metabolism, 84, 323-327. [PubMed: 9920102]

Madeira MD, Pereira PA, Silva SM, Cadete-Leite A, \& Paula-Barbosa MM (2004). Basal forebrain neurons modulate the synthesis and expression of neuropeptides in the rat suprachiasmatic nucleus. Neuroscience, 125, 889-901. 10.1016/j.neuroscience.2004.03.005 [PubMed: 15120850]

Marino M, Li Y, Rueschman MN, Winkelman JW, Ellenbogen JM, Solet JM, ... Buxton OM (2013). Measuring sleep: Accuracy, sensitivity, and specificity of wrist actigraphy compared to polysomnography. Sleep, 36, 1747-1755. 10.5665/sleep.3142 [PubMed: 24179309]

Martin LJ, Pan Y, Price AC, Sterling W, Copeland NG, Jenkins NA, ... Lee MK (2006). Parkinson's disease alpha-synuclein transgenic mice develop neuronal mitochondrial degeneration and cell death. Journal of Neuroscience, 26, 41-50. 10.1523/JNEUROSCI.4308-05.2006 [PubMed: 16399671]

McHill AW, Melanson EL, Higgins J, Connick E, Moehlman TM, Stothard ER, \& Wright KP Jr (2014). Impact of circadian misalignment on energy metabolism during simulated nightshift work. Proceedings of the National Academy of Sciences of the United States of America, 111, 1730217307. 10.1073/pnas.1412021111 [PubMed: 25404342]

McMullan CJ, Schernhammer ES, Rimm EB, Hu FB, \& Forman JP (2013). Melatonin secretion and the incidence of type 2 diabetes. JAMA: The Journal of the American Medical Association, 309, 1388-1396. 10.1001/jama.2013.2710 [PubMed: 23549584] 
Medeiros CA, Carvalhedo de Bruin PF, Lopes LA, Magalhaes MC, de Lourdes Seabra M, \& de Bruin VM (2007). Effect of exogenous melatonin on sleep and motor dysfunction in Parkinson's disease. A randomized, double blind, placebo-controlled study. Journal of Neurology, 254, 459-464. 10.1007/s00415-006-0390-x [PubMed: 17404779]

Menegaux F, Truong T, Anger A, Cordina-Duverger E, Lamkarkach F, Arveux P, ... Guenel P (2012). Night work and breast cancer: A population-based case-control study in France (the CECILE study). International Journal of Cancer, 132, 924-931. [PubMed: 22689255]

Minami Y, Kasukawa T, Kakazu Y, Iigo M, Sugimoto M, Ikeda S, ... Ueda HR (2009). Measurement of internal body time by blood metabolomics. Proceedings of the National Academy of Sciences of the United States of America, 106, 9890-9895. 10.1073/pnas.0900617106 [PubMed: 19487679]

Mishima K, Tozawa T, Satoh K, Matsumoto Y, Hishikawa Y, \& Okawa M (1999). Melatonin secretion rhythm disorders in patients with senile dementia of Alzheimer's type with disturbed sleepwaking. Biological Psychiatry, 45, 417-421. 10.1016/S0006-3223(97)00510-6 [PubMed: 10071710]

Miyazaki T, Hashimoto S, Masubuchi S, Honma S, \& Honma KI (2001). Phase-advance shifts of human circadian pacemaker are accelerated by daytime physical exercise. American Journal of Physiology. Regulatory, Integrative and Comparative Physiology, 281, R197-R205. 10.1152/ ajpregu.2001.281.1.R197

Moga MM, \& Moore RY (1997). Organization of neural inputs to the suprachiasmatic nucleus in the rat. The Journal of Comparative Neurology, 389, 508-534. 10.1002/ (SICI)1096-9861(19971222)389:3<508::AID-CNE11>3.0.CO;2-H [PubMed: 9414010]

Monti JM, \& Jantos H (2008). The roles of dopamine and serotonin, and of their receptors, in regulating sleep and waking. Progress in Brain Research, 172, 625-646. 10.1016/ S0079-6123(08)00929-1 [PubMed: 18772053]

Nagtegaal JE, Kerkhof GA, Smits MG, Swart AC, \& Van Der Meer YG (1998). Delayed sleep phase syndrome: A placebo-controlled cross-over study on the effects of melatonin administered five hours before the individual dim light melatonin onset. Journal of Sleep Research, 7, 135-143. 10.1046/j.1365-2869.1998.00102.x [PubMed: 9682186]

Neikrug AB, Rissling M, Trofimenko V, Liu L, Natarajan L, Lawton S, ... Ancoli-Israel S (2012). Bright light therapy protects women from circadian rhythm desynchronization during chemotherapy for breast cancer. Behavioral Sleep Medicine, 10, 202-216. 10.1080/15402002.2011.634940 [PubMed: 22742438]

Nguyen J, \& Wright KP Jr (2010). Influence of weeks of circadian misalignment on leptin levels. Nature and Science of Sleep, 2, 9-18.

Nyholm D, Lennernas H, Johansson A, Estrada M, \& Aquilonius SM (2010). Circadian rhythmicity in levodopa pharmacokinetics in patients with Parkinson disease. Clinical Neuropharmacology, 33, 181-185. 10.1097/WNF.0b013e3181e70f7a [PubMed: 20661024]

Okawa M, Mishima K, Hishikawa Y, Hozumi S, Hori H, \& Takahashi K (1991). Circadian rhythm disorders in sleep-waking and body temperature in elderly patients with dementia and their treatment. Sleep, 14, 478-485. 10.1093/sleep/14.6.478 [PubMed: 1798879]

Olcese JM, Cao C, Mori T, Mamcarz MB, Maxwell A, Runfeldt MJ, ... Arendash GW (2009). Protection against cognitive deficits and markers of neurodegeneration by long-term oral administration of melatonin in a transgenic model of Alzheimer disease. Journal of Pineal Research, 47, 82-96. 10.1111/j.1600-079X.2009.00692.x [PubMed: 19538338]

O'Leary ES, Schoenfeld ER, Stevens RG, Kabat GC, Henderson K, Grimson R, ... Electromagnetic Fields and Breast Cancer on Long Island Study Group (2006). Shift work, light at night, and breast cancer on Long Island, New York. American Journal of Epidemiology, 164, 358-366. 10.1093/aje/kwj211 [PubMed: 16777931]

Ono K, Mochizuki H, Ikeda T, Nihira T, Takasaki J, Teplow DB, \& Yamada M (2012). Effect of melatonin on alpha-synuclein self-assembly and cytotoxicity. Neurobiology of Aging, 33, 2172 2185. 10.1016/j.neurobiolaging.2011.10.015 [PubMed: 22118903]

Pagani L, Semenova EA, Moriggi E, Revell VL, Hack LM, Lockley SW, ... Brown SA (2010). The physiological period length of the human circadian clock in vivo is directly proportional to period in human fibroblasts. PLoS One, 5, e13376 10.1371/journal.pone.0013376 [PubMed: 21042402] 
Pan A, Schernhammer ES, Sun Q, \& Hu FB (2011). Rotating night shift work and risk of type 2 diabetes: Two prospective cohort studies in women. PLoS Medicine, 8, e1001141 10.1371/ journal.pmed.1001141 [PubMed: 22162955]

Pandi-Perumal SR, Smits M, Spence W, Srinivasan V, Cardinali DP, Lowe AD, \& Kayumov L (2007). Dim light melatonin onset (DLMO): A tool for the analysis of circadian phase in human sleep and chronobiological disorders. Progress in Neuro-Psychopharmacology \& Biological Psychiatry, 31, 1-11. 10.1016/j.pnpbp.2006.06.020 [PubMed: 16884842]

Patke A, Murphy PJ, Onat OE, Krieger AC, Ozcelik T, Campbell SS, \& Young MW (2017). Mutation of the human circadian clock gene CRY1 in familial delayed sleep phase disorder. Cell, 169, 203-215 e213. 10.1016/j.cell.2017.03.027 [PubMed: 28388406]

Paus S, Brecht HM, Koster J, Seeger G, Klockgether T, \& Wullner U (2003). Sleep attacks, daytime sleepiness, and dopamine agonists in Parkinson's disease. Movement Disorders, 18, 659-667. 10.1002/mds.10417 [PubMed: 12784269]

Paus S, Schmitz-Hubsch T, Wullner U, Vogel A, Klockgether T, \& Abele M (2007). Bright light therapy in Parkinson's disease: A pilot study. Movement Disorders, 22, 1495-1498. 10.1002/ (ISSN)1531-8257 [PubMed: 17516492]

Poeggeler B, Miravalle L, Zagorski MG, Wisniewski T, Chyan YJ, Zhang Y, ... Pappolla MA (2001). Melatonin reverses the profibrillogenic activity of apolipoprotein E4 on the Alzheimer amyloid Abeta peptide. Biochemistry, 40, 14995-15001. 10.1021/bi0114269 [PubMed: 11732920]

Pronk A, Ji BT, Shu XO, Xue S, Yang G, Li HL, ... Chow WH (2010). Night-shift work and breast cancer risk in a cohort of Chinese women. American Journal of Epidemiology, 171, 953-959. 10.1093/aje/kwq029 [PubMed: 20375193]

Puttonen S, Viitasalo K, \& Harma M (2012). The relationship between current and former shift work and the metabolic syndrome. Scandinavian Journal of Work, Environment \& Health, 38, 343348. 10.5271/sjweh.3267

Ramgopal S, Thome-Souza S, \& Loddenkemper T (2013). Chronopharmacology of anti-convulsive therapy. Current Neurology and Neuroscience Reports, 13, 339 10.1007/s11910-013-0339-2 [PubMed: 23456771]

Ranjan OP, Nayak UY, Reddy MS, Dengale SJ, Musmade PB, \& Udupa N (2013). Osmotically controlled pulsatile release capsule of montelukast sodium for chronotherapy: Statistical optimization, in vitro and in vivo evaluation. Drug Delivery, 21, 509-518. [PubMed: 24215165]

Reebs SG, \& Mrosovsky N (1989). Large phase-shifts of circadian rhythms caused by induced running in a re-entrainment paradigm: The role of pulse duration and light. Journal of Comparative Physiology. A, Sensory, Neural, and Behavioral Physiology, 165, 819-825. 10.1007/BF00610880

Reid KJ, Santostasi G, Baron KG, Wilson J, Kang J, \& Zee PC (2014). Timing and intensity of light correlate with body weight in adults. PLoS One, 9, e92251 10.1371/journal.pone.0092251 [PubMed: 24694994]

Reutrakul S, Hood MM, Crowley SJ, Morgan MK, Teodori M, Knutson KL, \& Van Cauter E (2013). Chronotype is independently associated with glycemic control in type 2 diabetes. Diabetes Care, 36, 2523-2529. 10.2337/dc12-2697 [PubMed: 23637357]

Riemersma-van der Lek RF, Swaab DF, Twisk J, Hol EM, Hoogendijk WJ, \& Van Someren EJ (2008). Effect of bright light and melatonin on cognitive and noncognitive function in elderly residents of group care facilities: A randomized controlled trial. JAMA: The Journal of the American Medical Association, 299, 2642-2655. 10.1001/jama.299.22.2642 [PubMed: 18544724]

Roenneberg T, Allebrandt KV, Merrow M, \& Vetter C (2012). Social jetlag and obesity. Current Biology: CB, 22, 939-943. 10.1016/j.cub.2012.03.038 [PubMed: 22578422]

Ruan GX, Allen GC, Yamazaki S, \& McMahon DG (2008). An autonomous circadian clock in the inner mouse retina regulated by dopamine and GABA. PLoS Biology, 6, e249 10.1371/ journal.pbio.0060249 [PubMed: 18959477]

Rutten S, Vriend C, van den Heuvel OA, Smit JH, Berendse HW, \& van der Werf YD (2012). Bright light therapy in Parkinson's disease: An overview of the background and evidence. Parkinson's Disease, 2012, 767105.

Rye DB (2004). The two faces of Eve: Dopamine's modulation of wakefulness and sleep. Neurology, 63, S2-S7. 10.1212/WNL.63.8_suppl_3.S2 
Sae-Ung K, Ueda K, Govitrapong P, \& Phansuwan-Pujito P (2012). Melatonin reduces the expression of alpha-synuclein in the dopamine containing neuronal regions of amphetamine-treated postnatal rats. Journal of Pineal Research, 52, 128-137. 10.1111/j.1600-079X.2011.00927.x [PubMed: 21851386]

Sakamoto K, Liu C, Kasamatsu M, Pozdeyev NV, Iuvone PM, \& Tosini G (2005). Dopamine regulates melanopsin mRNA expression in intrinsically photosensitive retinal ganglion cells. European Journal of Neuroscience, 22, 3129-3136. 10.1111/j.1460-9568.2005.04512.x [PubMed: 16367779]

Sarabia JA, Rol MA, Mendiola P, \& Madrid JA (2008). Circadian rhythm of wrist temperature in normal-living subjects A candidate of new index of the circadian system. Physiology \& Behavior, 95, 570-580. 10.1016/j.physbeh.2008.08.005 [PubMed: 18761026]

Schernhammer ES, Laden F, Speizer FE, Willett WC, Hunter DJ, Kawachi I, \& Colditz GA (2001). Rotating night shifts and risk of breast cancer in women participating in the nurses' health study. Journal of the National Cancer Institute, 93, 1563-1568. 10.1093/jnci/93.20.1563 [PubMed: 11604480]

Shanware NP, Hutchinson JA, Kim SH, Zhan L, Bowler MJ, \& Tibbetts RS (2011). Casein kinase 1dependent phosphorylation of familial advanced sleep phase syndrome-associated residues controls PERIOD 2 stability. The Journal of Biological Chemistry, 286, 12766-12774. 10.1074/ jbc.M111.224014 [PubMed: 21324900]

Shi SQ, Ansari TS, McGuinness OP, Wasserman DH, \& Johnson CH (2013). Circadian disruption leads to insulin resistance and obesity. Current Biology: CB, 23, 372-381. 10.1016/ j.cub.2013.01.048 [PubMed: 23434278]

Singer C, Tractenberg RE, Kaye J, Schafer K, Gamst A, Grundman M, ... Thal LJ (2003). A multicenter, placebo-controlled trial of melatonin for sleep disturbance in Alzheimer's disease. Sleep, 26, 893-901. 10.1093/sleep/26.7.893 [PubMed: 14655926]

Skene DJ, \& Swaab DF (2003). Melatonin rhythmicity: Effect of age and Alzheimer's disease. Experimental Gerontology, 38, 199-206. 10.1016/S0531-5565(02)00198-5 [PubMed: 12543278]

Skene DJ, Vivien-Roels B, Sparks DL, Hunsaker JC, Pevet P, Ravid D, \& Swaab DF (1990). Daily variation in the concentration of melatonin and 5-methoxytryptophol in the human pineal gland: Effect of age and Alzheimer's disease. Brain Research, 528, 170-174. 10.1016/0006-8993(90)90214-V [PubMed: 2245336]

Sohail S, Yu L, Bennett DA, Buchman AS, \& Lim AS (2015). Irregular 24-hour activity rhythms and the metabolic syndrome in older adults. Chronobiology International, 32, 802-813. 10.3109/07420528.2015.1041597 [PubMed: 26061588]

van Someren EJ, Hagebeuk EE, Lijzenga C, Scheltens P, de Rooij SE, Jonker C, ... Swaab DF (1996). Circadian rest-activity rhythm disturbances in Alzheimer's disease. Biological Psychiatry, 40, 259-270. 10.1016/0006-3223(95)00370-3 [PubMed: 8871772]

Stopa EG, Volicer L, Kuo-Leblanc V, Harper D, Lathi D, Tate B, \& Satlin A (1999). Pathologic evaluation of the human suprachiasmatic nucleus in severe dementia. Journal of Neuropathology and Experimental Neurology, 58, 29-39. 10.1097/00005072-199901000-00004 [PubMed: 10068311]

Straif K, Baan R, Grosse Y, Secretan B, El Ghissassi F, Bouvard V, ... Cogliano V (2007). Carcinogenicity of shift-work, painting, and fire-fighting. The Lancet Oncology, 8, 1065-1066. 10.1016/S1470-2045(07)70373-X [PubMed: 19271347]

Stranahan AM (2012). Chronobiological approaches to Alzheimer's disease. Current Alzheimer Research, 9, 93-98. 10.2174/156720512799015028 [PubMed: 22329654]

Stuebner E, Vichayanrat E, Low DA, Mathias CJ, Isenmann S, \& Haensch CA (2013). Twenty-four hour non-invasive ambulatory blood pressure and heart rate monitoring in Parkinson's disease. Frontiers in Neurology, 4, 49. [PubMed: 23720648]

Swaab DF, Fliers E, \& Partiman TS (1985). The suprachiasmatic nucleus of the human brain in relation to sex, age and senile dementia. Brain Research, 342, 37-44. 10.1016/0006-8993(85)91350-2 [PubMed: 4041816] 
Toh KL, Jones CR, He Y, Eide EJ, Hinz WA, Virshup DM, ... Fu YH (2001). An hPer2 phosphorylation site mutation in familial advanced sleep phase syndrome. Science, 291, 10401043. 10.1126/science.1057499 [PubMed: 11232563]

Tractenberg RE, Singer CM, \& Kaye JA (2006). Characterizing sleep problems in persons with Alzheimer's disease and normal elderly. Journal of Sleep Research, 15, 97-103. 10.1111/ j.1365-2869.2006.00499.x [PubMed: 16490008]

Tranah GJ, Blackwell T, Stone KL, Ancoli-Israel S, Paudel ML, Ensrud KE, ... Yaffe K (2011). Circadian activity rhythms and risk of incident dementia and mild cognitive impairment in older women. Annals of Neurology, 70, 722-732. 10.1002/ana.22468 [PubMed: 22162057]

Turner PL, \& Mainster MA (2008). Circadian photoreception: Ageing and the eye's important role in systemic health. British Journal of Ophthalmology, 92, 1439-1444. 10.1136/bjo.2008.141747 [PubMed: 18757473]

Tynes T, Hannevik M, Andersen A, Vistnes AI, \& Haldorsen T (1996). Incidence of breast cancer in Norwegian female radio and telegraph operators. Cancer Causes \& Control: CCC, 7, 197-204. 10.1007/BF00051295

Ueda HR, Chen W, Minami Y, Honma S, Honma K, Iino M, \& Hashimoto S (2004). Moleculartimetable methods for detection of body time and rhythm disorders from single-time-point genome-wide expression profiles. Proceedings of the National Academy of Sciences of the United States of America, 101, 11227-11232. 10.1073/pnas.0401882101 [PubMed: 15273285]

Van Someren EJ (2000). Circadian and sleep disturbances in the elderly. Experimental Gerontology, 35, 1229-1237. 10.1016/S0531-5565(00)00191-1 [PubMed: 11113604]

Videnovic A, Klerman EB, Wang W, Marconi A, Kuhta T, \& Zee PC (2017). Timed light therapy for sleep and daytime sleepiness associated with Parkinson disease: A randomized clinical trial. JAMA Neurology, 74, 411-418. 10.1001/jamaneurol.2016.5192 [PubMed: 28241159]

Videnovic A, Noble C, Reid KJ, Peng J, Turek FW, Marconi A, ... Zee PC (2014). Circadian melatonin rhythm and excessive daytime sleepiness in Parkinson disease. JAMA Neurology, 71, 463-469. 10.1001/jamaneurol.2013.6239 [PubMed: 24566763]

Volicer L, Harper DG, Manning BC, Goldstein R, \& Satlin A (2001). Sundowning and circadian rhythms in Alzheimer's disease. American Journal of Psychiatry, 158, 704-711. 10.1176/ appi.ajp.158.5.704 [PubMed: 11329390]

Voultsios A, Kennaway DJ, \& Dawson D (1997). Salivary melatonin as a circadian phase marker: Validation and comparison to plasma melatonin. Journal of Biological Rhythms, 12, 457-466. 10.1177/074873049701200507 [PubMed: 9376644]

Wailke S, Herzog J, Witt K, Deuschl G, \& Volkmann J (2011). Effect of controlled-release levodopa on the microstructure of sleep in Parkinson's disease. European Journal of Neurology, 18, 590596. 10.1111/j.1468-1331.2010.03213.x [PubMed: 20849470]

Wang YC, \& Huang RC (2006). Effects of sodium pump activity on spontaneous firing in neurons of the rat suprachiasmatic nucleus. Journal of Neurophysiology, 96, 109-118. 10.1152/ jn.01369.2005 [PubMed: 16467417]

Wang JL, Lim AS, Chiang WY, Hsieh WH, Lo MT, Schneider JA, ... Saper CB (2015). Suprachiasmatic neuron numbers and rest-activity circadian rhythms in older humans. Annals of Neurology, 78, 317-322. 10.1002/ana.24432 [PubMed: 25921596]

Wang DL, Ling ZQ, Cao FY, Zhu LQ, \& Wang JZ (2004). Melatonin attenuates isoproterenol-induced protein kinase A overactivation and tau hyperphosphorylation in rat brain. Journal of Pineal Research, 37, 11-16. 10.1111/j.1600-079X.2004.00130.x [PubMed: 15230863]

Wang HB, Loh DH, Whittaker DS, Cutler T, Howland D, \& Colwell CS (2018). Time-restricted feeding improves circadian dysfunction as well as motor symptoms in the Q175 mouse model of Huntington's disease. ENeuro, 5(1), e0431-17.2017 1-16.

Watanabe M, Hida A, Kitamura S, Enomoto M, Ohsawa Y, Katayose Y, ... Mishima K (2012). Rhythmic expression of circadian clock genes in human leukocytes and beard hair follicle cells. Biochemical and Biophysical Research Communications, 425, 902-907. 10.1016/ j.bbrc.2012.08.008 [PubMed: 22902636] 
Whitehead DL, Davies AD, Playfer JR, \& Turnbull CJ (2008). Circadian rest-activity rhythm is altered in Parkinson's disease patients with hallucinations. Movement Disorders, 23, 1137-1145. 10.1002/mds.22057 [PubMed: 18442142]

Willis GL, Moore C, \& Armstrong SM (2012). A historical justification for and retrospective analysis of the systematic application of light therapy in Parkinson's disease. Reviews in the Neurosciences, 23, 199-226. [PubMed: 22499678]

Wittenbrink N, Ananthasubramaniam B, Munch M, Koller B, Maier B, Weschke C, ... Kramer A (2018). High-accuracy determination of internal circadian time from a single blood sample. Journal of Clinical Investigation, 128, 3826-3839. 10.1172/JCI120874 [PubMed: 29953415]

Witting W, Kwa IH, Eikelenboom P, Mirmiran M, \& Swaab DF (1990). Alterations in the circadian rest-activity rhythm in aging and Alzheimer's disease. Biological Psychiatry, 27, 563-572. 10.1016/0006-3223(90)90523-5 [PubMed: 2322616]

Wittmann M, Dinich J, Merrow M, \& Roenneberg T (2006). Social jetlag: Misalignment of biological and social time. Chronobiology International, 23, 497-509. 10.1080/07420520500545979 [PubMed: 16687322]

Wu LM, Amidi A, Valdimarsdottir H, Ancoli-Israel S, Liu L, Winkel G, ... Redd WH (2018). The effect of systematic light exposure on sleep in a mixed group of fatigued cancer survivors. Journal of Clinical Sleep Medicine, 14, 31-39. 10.5664/jcsm.6874 [PubMed: 29198295]

Wyse CA, Celis Morales CA, Graham N, Fan Y, Ward J, Curtis AM, ... Pell JP (2017). Adverse metabolic and mental health outcomes associated with shiftwork in a population-based study of 277,168 workers in UK biobank(). Annals of Medicine, 49, 411-420. 10.1080/07853890.2017.1292045 [PubMed: 28166415]

Xie L, Kang H, Xu Q, Chen MJ, Liao Y, Thiyagarajan M, ... Nedergaard M (2013). Sleep drives metabolite clearance from the adult brain. Science, 342, 373-377. 10.1126/science.1241224 [PubMed: 24136970]

Xu Y, Padiath QS, Shapiro RE, Jones CR, Wu SC, Saigoh N, ... Fu YH (2005). Functional consequences of a CKIdelta mutation causing familial advanced sleep phase syndrome. Nature, 434, 640-644. 10.1038/nature03453 [PubMed: 15800623]

Yannielli P, \& Harrington ME (2004). Let there be "more" light: Enhancement of light actions on the circadian system through nonphotic pathways. Progress in Neurobiology, 74, 59-76. 10.1016/ j.pneurobio.2004.06.001 [PubMed: 15381317]

Zee PC, \& Vitiello MV (2009). Circadian rhythm sleep disorder: Irregular sleep wake rhythm type. Sleep Medicine Clinics, 4, 213-218. 10.1016/j.jsmc.2009.01.009 [PubMed: 20160950]

Zhang R, Lahens NF, Ballance HI, Hughes ME, \& Hogenesch JB (2014). A circadian gene expression atlas in mammals: Implications for biology and medicine. Proceedings of the National Academy of Sciences of the United States of America, 111, 16219-16224. 10.1073/pnas.1408886111 [PubMed: 25349387]

Zhong G, Bolitho S, Grunstein R, Naismith SL, \& Lewis SJ (2013). The relationship between thermoregulation and REM sleep behaviour disorder in Parkinson's disease. PLoS One, 8, e72661 10.1371/journal.pone.0072661 [PubMed: 23991135]

Zhou JN, Hofman MA, \& Swaab DF (1995). VIP neurons in the human SCN in relation to sex, age, and Alzheimer's disease. Neurobiology of Aging, 16, 571-576. 10.1016/0197-4580(95)00043-E [PubMed: 8544907]

Zhou JN, Liu RY, Kamphorst W, Hofman MA, \& Swaab DF (2003). Early neuropathological Alzheimer')s changes in aged individuals are accompanied by decreased cerebrospinal fluid melatonin levels. Journal of Pineal Research, 35, 125-130. 10.1034/j.1600-079X.2003.00065.x [PubMed: 12887656] 


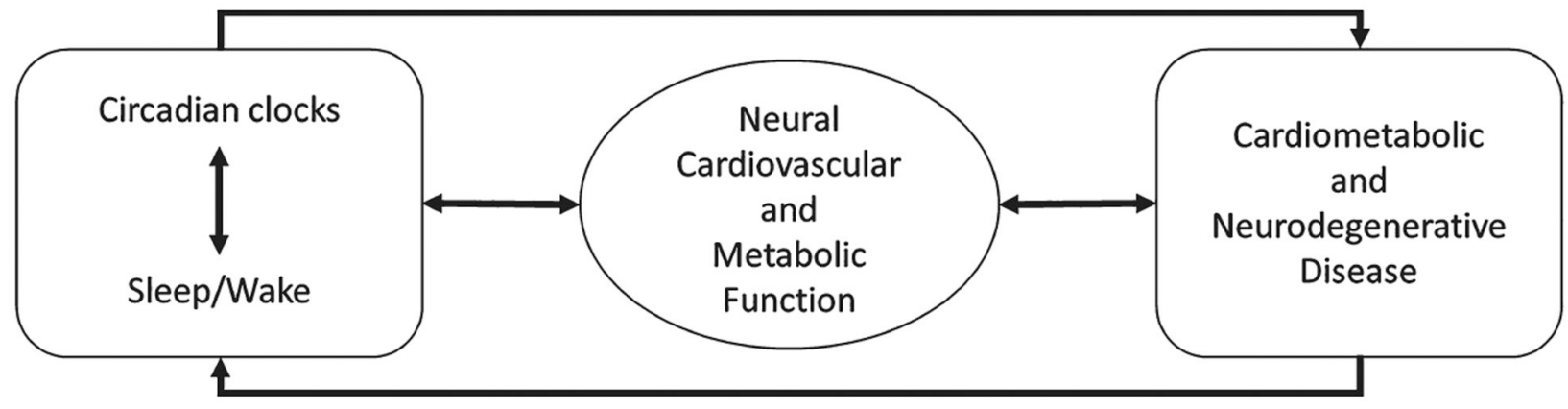

1. Circadian and sleep-wake function are essential for cell function, neural connectivity and plasticity

2. Circadian and sleep disruption contribute to cardio-metabolic and brain disorders common with aging

3. Synchronizing central and peripheral clocks can serve as targets for disease prevention and modification.

FIGURE 1.

The link between circadian disruption and human health is bidirectional 